\title{
Synthesis of GO-modified $\mathrm{Cu}_{2} \mathrm{O}$ nanosphere and the photocatalytic mechanism of water splitting for hydrogen production \\ Ying Huang ${ }^{1,2}$, Chang-Feng Yan ${ }^{1,2, *}$, Chang-Qing Guo ${ }^{1}$, Zhuo-Xin $\mathrm{Lu}^{1,2}$, Yan Shi ${ }^{1}$, Zhi-Da \\ Wang ${ }^{1}$ \\ ${ }^{1}$ Guangzhou Institute of Energy Conversion, Chinese Academy of Sciences, Guangdong, 510640, China \\ ${ }^{2}$ University of Chinese Academy of Sciences, Beijing, 100039 China \\ *E-mail: yancf@ms.giec.ac.cn
}

\begin{abstract}
A new one-step method for synthesize cuprous oxide nanosphere without any additive surfactant in room temperature and atmospheric pressure was carried. The nanospheres with the diameters less than $100 \mathrm{~nm}$ were well-dispersed and formed the core-shell structure with the GO. The partial reduction of GO increases the atomic percentage of $\mathrm{sp}^{2}$ carbon (graphene sheets). It was found that $\mathrm{sp}^{2}$ carbon with better conductivity plays an important role in mitigating electron-hole recombination and enhancing electron transfer between $\mathrm{Cu}_{2} \mathrm{O}$ and $\mathrm{GO}$ and thus enhance the photocatalytic activity. The highest hydrogen yields for GO-modified samples $(118.3 \mu \mathrm{mol})$ were more than twice as large as that of bare $\mathrm{Cu}_{2} \mathrm{O}$ nanosphere $(44.6 \mu \mathrm{mol})$.
\end{abstract}

Key words: $\mathrm{Cu}_{2} \mathrm{O}$ nanosphere, graphene oxide, photocatalyst, hydrogen, water splitting

\section{Introduction}

Solar energy has been caught much attention for global researchers because it is renewable, carbon-free and the largest source available among all the developing renewable energy sources [1]. The common way of utilizing solar energy is to convert it into electricity by photo-voltaic cells [2], while the other routine is to convert it into chemical energy, such as hydrogen [3], methanol [4], or carbon monoxide [5], directly by photocatalysts. Since the first photocatalyst, $\mathrm{TiO}_{2}$, used for hydrogen production during the water splitting reaction was reported at 1972 [6], $\mathrm{TiO}_{2}$ has been explored as a stable, efficient and nontoxic photocatalyst or support. However, its large band gap $(3.2 \mathrm{eV})$ has constrained its further utilization as the commercial catalyst for photocatalytic hydrogen production.

The p-type semiconductor cuprous oxide $\left(\mathrm{Cu}_{2} \mathrm{O}\right)$ with a direct band gaps of 1.9 2.2 eV[7-9] is a kind of widely-used photocatalyst for pollutant degradation [9-13], carbon dioxide reduction [5, 14-17] and water splitting for hydrogen production [2, 8, 18-21]. Its narrower band gap, higher visible light absorption and better electron-hole separation suggests it can be a more potential photocatalyst than $\mathrm{TiO}_{2}$ $[17,21]$. For further research in the morphology, $\mathrm{Cu}_{2} \mathrm{O}$ sphere has larger specific surface area and higher photocatalytic performance than those of $\mathrm{Cu}_{2} \mathrm{O}$ cubic or bulk [22-24]. Many reported methods to form $\mathrm{Cu}_{2} \mathrm{O}$ spheres need various kinds of surfactant, such as Polyvinyl Pyrrolidone (PVP) and Cetyltrimethyl Ammonium Bromide (CTAB) during hydrothermal [2, 15, 25] or solvothermal treatment $[11,26]$. Uniform shapes would be obtained in these methods, however, expensive surfactants and extended period would also be cost. Besides, all shapes of $\mathrm{Cu}_{2} \mathrm{O}$ can be easily oxidized to $\mathrm{CuO}$ or other compounds and lost the ability to produce hydrogen. Thus, modified surface of $\mathrm{Cu}_{2} \mathrm{O}$ and improved synthetic methods are needed.

Graphene oxide (GO) has been proved as the potential carbonaceous solid support or cocatalyst $[2,8,18$, $19,27]$ to enhance the photocatalytic activities of $\mathrm{Cu}_{2} \mathrm{O}$. Graphene oxide (GO) is derived from extensive oxidation of graphite in chemical oxidation methods. The sheets of GO can be easily dispersed or exfoliated in aqueous solution because they contains hydrophilic oxygen functional groups on 
constituting graphene sheets.[28] The photoelectronic properties of GO are related to the composition of oxygen bonding on graphene sheets and these sheets were able to grow on the surface of $\mathrm{Cu}_{2} \mathrm{O}$ due to some oxygen composition. So the photoelectrons can be easily transfer from $\mathrm{Cu}_{2} \mathrm{O}$ to $\mathrm{GO}$ sheets [29] and reduced electron-hole recombination by constructing heterojunctions [1].

Some similar works on $\mathrm{Cu}_{2} \mathrm{O} / \mathrm{RGO}$ photocatalysts for hydrogen production have been reported [30-32] It was found that $\mathrm{Cu}_{2} \mathrm{O}$ on $\mathrm{RGO}$ sheet can promote the separation of electrons and holes pairs by efficiently trapping the accumulated electrons [30]. The graphene sheets was utilized as an electron accepter and formed a p-n junction with $\mathrm{Cu}_{2} \mathrm{O}$ [31]. And it plays an important role in synergistically absorbing visible light, suppressing the charge recombination and enhancing the crystallinity [32]. However, the synergistic effect and the photocatalytic mechanism of GO-modified $\mathrm{Cu}_{2} \mathrm{O}$ nanospheres have not be clearly discussed.

In this paper, a one-step method for synthesize cuprous oxide nanosphere without any additive surfactant in room temperature and atmospheric pressure was proved to be an effective and low-cost method. The diameter of the nanosphere was less than $100 \mathrm{~nm}$. In order to investigate the structure of GO-modified $\mathrm{Cu}_{2} \mathrm{O}$ nanospheres synthesized in this method and the photocatalytic mechanism, XRD, Raman spectra, XPS, SEM, UV-Vis and PL were carried. It was found out that the GO sheets were well-dispersed and formed the core-shell structure with $\mathrm{Cu}_{2} \mathrm{O}$ nanospheres. The positive conduction band edge potentials of all GO-modified sample were turning to negative potential region during irradiation, which is attributed to the partial reduction of GO sheets. Further research found that the increased atomic percentage of $\mathrm{sp}^{2}$ carbon (graphene sheets) with better conductivity plays an important role in mitigating electron-hole recombination and enhancing electron transfer between $\mathrm{Cu}_{2} \mathrm{O}$ and $\mathrm{GO}$, which leads to the enhancement of photocatalytic activity. The highest hydrogen yields for GO-modified samples (118.3 $\mu$ mol) were more than twice as large as that of bare $\mathrm{Cu}_{2} \mathrm{O}$ nanosphere $(44.6 \mu \mathrm{mol})$.

\section{Experimental}

\subsection{Preparation of graphene oxide (GO)}

GO was prepared using a modified Hummers method from graphite powders.[25, 33, 34] $0.5 \mathrm{~g}$ of graphite, $0.5 \mathrm{~g}$ of $\mathrm{NaNO}_{3}$, and $23 \mathrm{~mL}$ of concentrated $\mathrm{H}_{2} \mathrm{SO}_{4}$ were stirred together in an ice water bath. Then, $3 \mathrm{~g}$ of $\mathrm{KMnO}_{4}$ was added into the above mixture under $0{ }^{\circ} \mathrm{C}$. The solution was the stirred for about 1.5 hours at $35^{\circ} \mathrm{C}$. After the main reaction was completed, $40 \mathrm{~mL}$ of deionized water was slowly dropped into the above solution while the temperature was raised to $90{ }^{\circ} \mathrm{C}$. After stirring for 30 minutes, another $10 \mathrm{~mL} \mathrm{H}_{2} \mathrm{O}_{2}$ and $40 \mathrm{~mL}$ of deionized water was dropped in, respectively, and the color of the mixture changed from brown to yellow. Then the mixture was centrifuged at $6000 \mathrm{rpm}$ for $10 \mathrm{~min}$. Then the obtained yellow transparent liquid was filtered by a microporous barrier filter, and the solid was washed repeatedly using $5 \% \mathrm{HCl}$ solution until the sulfate could not be detected in the solution through standard barium chloride precipitation test. The above product was sequentially washed using distilled water until the $\mathrm{pH}$ value of washed water was approximated to 7. Finally, the solid GO was supersonic dispersed in deionized water.

\subsection{Preparation of GO-modified $\mathrm{Cu}_{2} \mathrm{O}$ nanosphere}

The GO-modified $\mathrm{Cu}_{2} \mathrm{O}$ nanosphere was synthesized under room temperature by using hydrazine hydrate as the reductive agent. $0.3 \mathrm{~g}$ of cupric citrate and $150 \mathrm{ml}$ of deionized water were stirred for 15 minutes. Then GO dispersion was added to the above mixture and kept stirring for 2 hours. Then $1.43 \mathrm{ml}$ of hydrazine hydrate (80 vol.\%) was diluted to $100 \mathrm{ml}$ aqueous solution and then slowly dropped to 
above mixture and kept stirring for 40 minutes. Finally, after filtration, washing and vacuum drying, the dark green powder was prepared. The GO-modified samples with 0.1 wt. $\%, 0.5$ wt. $\%$ and 1 wt. $\%$ of GO addition were denoted as $\mathrm{GO} / \mathrm{Cu}_{2} \mathrm{O}-0.1, \mathrm{GO} / \mathrm{Cu}_{2} \mathrm{O}-0.5$ and $\mathrm{GO} / \mathrm{Cu}_{2} \mathrm{O}-1$, respectively. The bare $\mathrm{Cu}_{2} \mathrm{O}$ nanosphere (denoted as $\mathrm{Cu}_{2} \mathrm{O}-\mathrm{NS}$ ) was prepared without $\mathrm{GO}$ addition and the RGO synthesized for comparison was prepared without cupric citrate addition. In this method, no surfactant was added and the formation of nanosphere shape may be attributed to the clathration of $\mathrm{Cu}^{2+}$ and citrate.

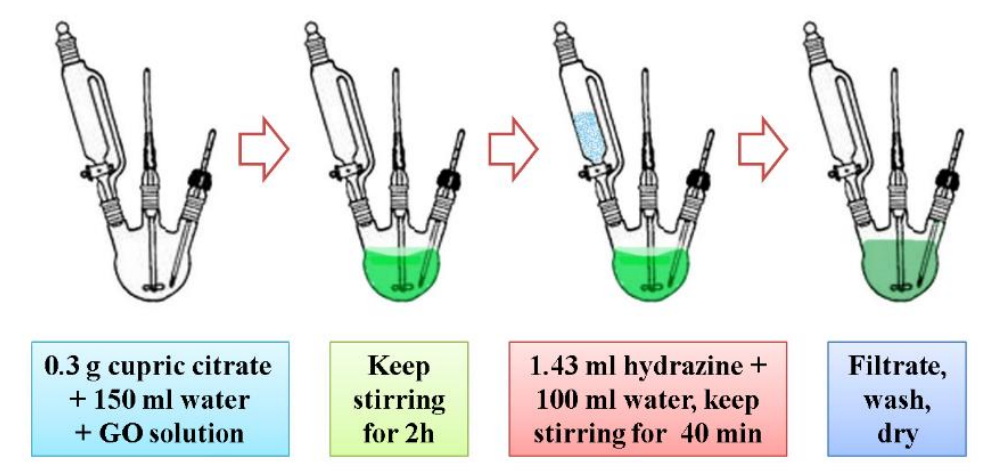

Figure 1. Preparation of $\mathrm{Cu}_{2} \mathrm{O}$ nanospheres and the GO-modified samples.

\subsection{Characterization}

X-ray diffraction (XRD) analysis was performed with the PANalytical X'Pert diffractometer (X'Pert PRO MPD, PW3040/60) within the $2-\theta$ ranged from $5^{\circ}$ to $80^{\circ}$ by a speed of $6^{\circ}$ per minute with $\mathrm{Cu}-\mathrm{K} \alpha(\lambda$ $=0.154060 \mathrm{~nm})$ radiation $(40 \mathrm{kV}, 40 \mathrm{~mA})$. The crystallite size was calculated by the Scherrer equation from the XRD spectra. UV-vis spectroscopy in the $300 \mathrm{~nm}-800 \mathrm{~nm}$ was measured with a Lambda 750 Diffuse Reflectance Spectroscopy. X-Ray photoelectron spectroscopy (XPS) analysis were conducted through a thermo ESCALAB 250XI multifunctional imaging electron spectrometer (Thermo Fisher Scientific Inc.) equipped with an $\mathrm{Al}$ K radiation source. UV-vis spectroscopy in the region of $300 \mathrm{~nm}-800$ nm was measured with a Lambda 750 Diffuse Reflectance Spectroscopy. Fluorescence spectra were obtained using a photoluminescence (PL) spectrometer (Perkin Elmer, LS-55). The concentration of methanol and ethanol were detected by a gas chromatograph (GC-7890II), equipped a flame ionization detector and a stainless steel packed column (PorapakQ, $2 \mathrm{~mm} \times 1 \mathrm{~m}$ ).

\subsection{Photocatalytic reaction testing}

Photocatalytic reactions for overall water splitting were carried out in a $15 \mathrm{~mL}$ quartz cell with a $25 \mathrm{~mm} \times$ $25 \mathrm{~mm}$ window for light transmission at room temperature under visible light irradiation $(\lambda>400 \mathrm{~nm}$, $\approx 0.1 \mathrm{~W} / \mathrm{cm}^{2}$ ). The catalyst powder (30 mg) was suspended in $10 \mathrm{vol}$. \% methanol aqueous solution (15 $\mathrm{mL}$ ) by magnetic stirring. In this paper, methanol plays a role as the sacrifice agent to scavenge photo-generated holes. The evolved gases were determined with a gas chromatograph equipped with a TCD detector.

\section{Results and Discussion}

\subsection{Characterization of $\mathrm{GO} / \mathrm{Cu}_{2} \mathrm{O}$}



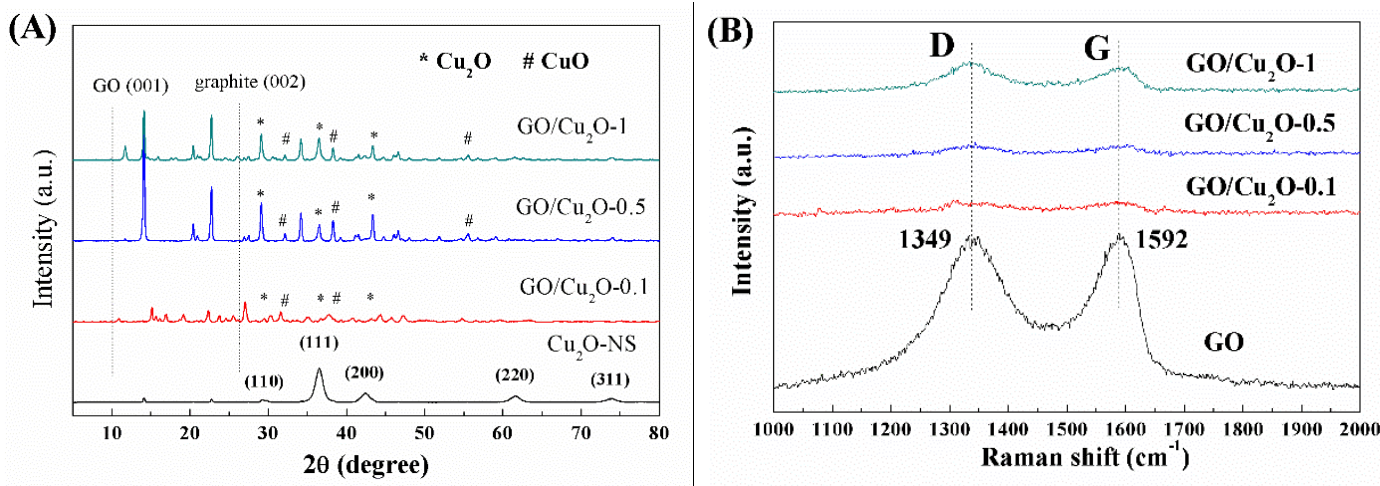

Figure 2. XRD patterns (A) of $\mathrm{Cu}_{2} \mathrm{O}$-NS and the GO-modified samples and Raman patterns (B) of $\mathrm{GO}$ and the GO-modified samples

The XRD patterns of $\mathrm{Cu}_{2} \mathrm{O}-\mathrm{NS}$ and the GO-modified samples are shown in Figure 2(A). Five strong peaks belong to cubic phase of $\mathrm{Cu}_{2} \mathrm{O}$ (Reference code: 03-065-3288) are corresponding respectively to (110), (111), (200), (220) and (331) planes. It indicates the crystallization of $\mathrm{Cu}_{2} \mathrm{O}-\mathrm{NS}$ did not restrain by the strong reducibility of hydrazine. However, the XRD patterns of the GO-modified samples are much more complicated, because no only $\mathrm{Cu}_{2} \mathrm{O}$ and $\mathrm{CuO}$ peaks were detected, but also many indistinguishable peaks were found from 10 to 30 degree. It may be attributed to the groups on the surface of graphene oxide and some other copper compound. Among the XRD patterns of the GO-modified samples, no graphite peaks $\left(26.6^{\circ}, 002\right)$ and metal copper peaks $\left(43.38^{\circ}, 111 ; 50.50^{\circ}, 200\right)[35]$ are observed , and the weak peaks at around $2 \theta=10.6^{\circ}$ corresponds to the reflection (001) plane of GO[25].

Figure 2(B) shows two characteristic bands arising from GO and the GO-modified samples. The D band $\left(\sim 1350 \mathrm{~cm}^{-1}\right)$ and the $\mathrm{G}$ band $\left(\sim 1590 \mathrm{~cm}^{-1}\right)$, identical to the bare $\mathrm{GO}$ nano-sheets. The $\mathrm{D}$ band results from disorder in the symmetrical hexagonal graphitic lattice, while the $\mathrm{G}$ band originates from the in-plane stretching motion of symmetric $\mathrm{sp}^{2} \mathrm{C}-\mathrm{C}$ bonds.[25] The intensity of D and $\mathrm{G}$ bands for GO-modified samples are weak because of the small amount of GO addition. The D/G intensity ratios for GO, $\mathrm{GO} / \mathrm{Cu}_{2} \mathrm{O}-0.1, \mathrm{GO} / \mathrm{Cu}_{2} \mathrm{O}-0.5$ and $\mathrm{GO} / \mathrm{Cu}_{2} \mathrm{O}-1$ are $0.98,0.93,1.05$ and 1.17 , respectively. The ratios for the GO-modified samples are close to that of GO, it suggests that little of the doped $\mathrm{GO}$ are reduced. The ratios for $\mathrm{GO} / \mathrm{Cu}_{2} \mathrm{O}-0.5$ and $\mathrm{GO} / \mathrm{Cu}_{2} \mathrm{O}-1$ are slightly larger than that of $\mathrm{GO}$. It indicates the $\mathrm{GO}$ were partly reduced to graphene or some other carbon species [36]. The D/G intensity ratio increases with the increasing of the GO addition, which may be attributed to the formation of $\mathrm{GO}$ shell and $\mathrm{Cu}_{2} \mathrm{O}$ core structure because the $\mathrm{GO}$ shell will prevent further reduction of $\mathrm{Cu}_{2} \mathrm{O}$ core and then consume larger part of hydrazine during synthesis. The cover of $\mathrm{GO}$ also results in the incomplete reduction of $\mathrm{Cu}$ (II) and forms $\mathrm{CuO}$ for all the GO-modified samples.

Table 1-Texture properties of $\mathrm{Cu}_{2} \mathrm{O}$ nanosphere and the GO-modified samples.

\begin{tabular}{ccccc} 
Sample & $\begin{array}{c}\text { BET surface } \\
\text { area }\left(\mathbf{m}^{2} / \mathbf{g}\right)\end{array}$ & $\begin{array}{c}\text { Average pore } \\
\text { diameter }(\mathbf{n m})\end{array}$ & $\begin{array}{c}\text { Total pore } \\
\text { volume }\left(\mathbf{c m}^{\mathbf{3}} \mathbf{g}^{-\mathbf{1}}\right)\end{array}$ & $\begin{array}{c}\text { The crystallite } \\
\text { size of } \mathbf{C u}_{\mathbf{2}} \mathbf{O} \\
(\mathbf{n m})\end{array}$ \\
\hline $\mathbf{C u} \mathbf{2} \mathbf{O}-\mathbf{N S}$ & 23.8 & 6.22 & 0.16 & 7.22 \\
$\mathbf{G O} / \mathbf{C u}_{\mathbf{2}} \mathbf{O}-\mathbf{0 . 1}$ & 14.1 & 3.45 & 0.08 & 9.93 \\
$\mathbf{G O} / \mathbf{C u}_{\mathbf{2}} \mathbf{O}-\mathbf{0 . 5}$ & 19.3 & 3.07 & 0.11 & 22.71 \\
$\mathbf{G O} / \mathbf{C u}_{\mathbf{2}} \mathbf{O}-\mathbf{1}$ & 14.2 & 3.06 & 0.08 & 19.87 \\
\hline
\end{tabular}



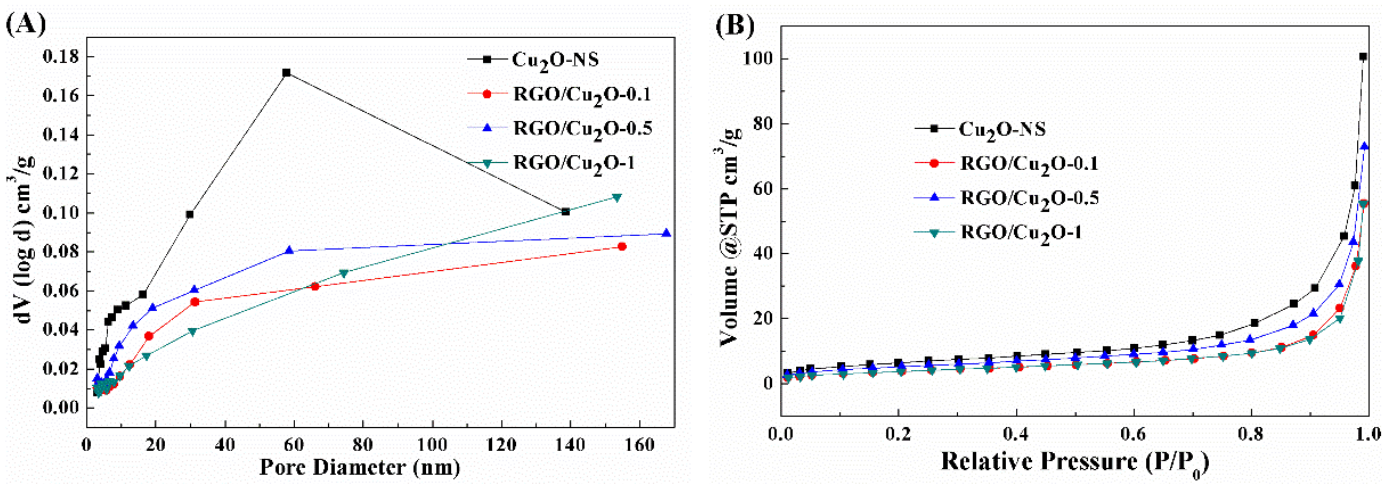

Figure 3. Pore size distribution curve (A) and nitrogen adsorption isotherms (B) of $\mathrm{Cu}_{2} \mathrm{O}$ nanosphere and the GO-modified samples.

Table 3 shows the texture properties of $\mathrm{Cu}_{2} \mathrm{O}$ nanosphere and the GO-modified samples, including BET surface area, average pore diameter, total pore volume and the crystallite sizes of $\mathrm{Cu}_{2} \mathrm{O}$ calculated by Debye-Scherrer equation. After doping GO, the BET surface areas, average pore diameter and total pore volume decrease sharply while the crystallite size of $\mathrm{Cu}_{2} \mathrm{O}$ increase from 7.22 to $22.71 \mathrm{~nm}$. The groups on the surface of GO sheets may obstruct the clathration of $\mathrm{Cu}^{2+}$ and citrate, which leads to agglomeration of copper oxides particles and cover of mesoporous. However, the pore size distribution curve (Figure 3 (A)) shows that the pore distribution of mesoporous were similar, and both of the order of the mesoporous amounts $(\mathrm{dV}(\operatorname{logd})$ value) and the order of nitrogen adsorption volumes (Figure $3(\mathrm{~B})$ ) were $\mathrm{Cu}_{2} \mathrm{O}-\mathrm{NS}>\mathrm{GO} / \mathrm{Cu}_{2} \mathrm{O}-0.5>\mathrm{GO} / \mathrm{Cu}_{2} \mathrm{O}-0.1>\mathrm{GO} / \mathrm{Cu}_{2} \mathrm{O}-1$. The mesoporous amounts and nitrogen absorption volumes of the GO-modified samples were less than those of $\mathrm{Cu}_{2} \mathrm{O}-\mathrm{NS}$, which indicates that $\mathrm{GO}$ was cover on the surface of $\mathrm{Cu}_{2} \mathrm{O}$ nanospheres and it might be formed a kind of core-shell structure. Besides, $\mathrm{GO} / \mathrm{Cu}_{2} \mathrm{O}-0.5$ has the largest surface area and total pore volume and the smallest average pore diameter among all GO-modified samples, and its expected photocatalytic activity might be the best of all.
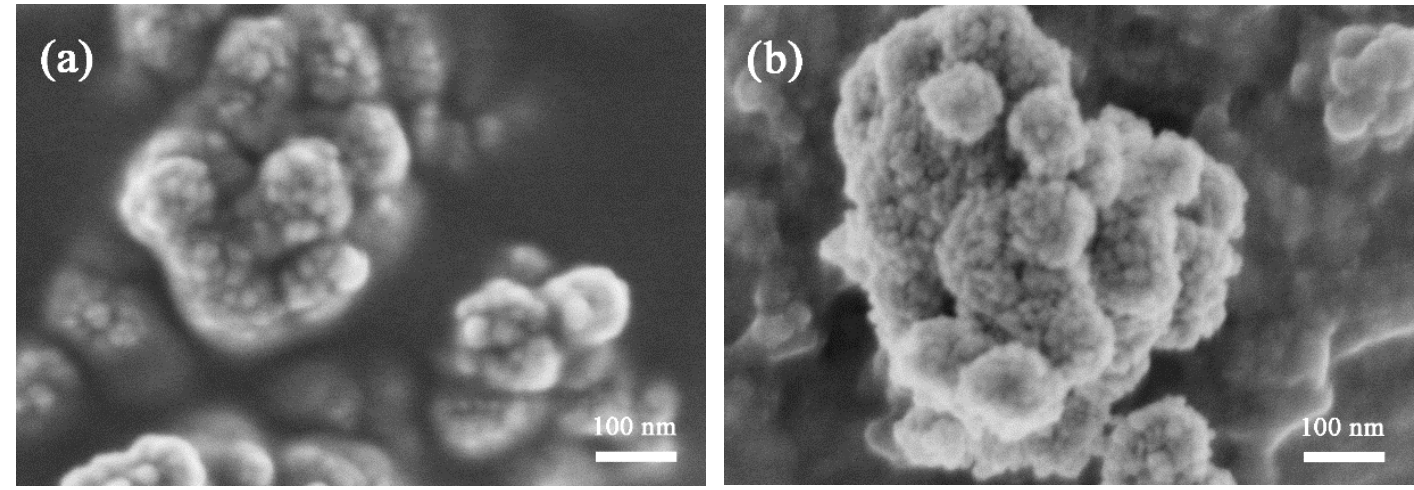

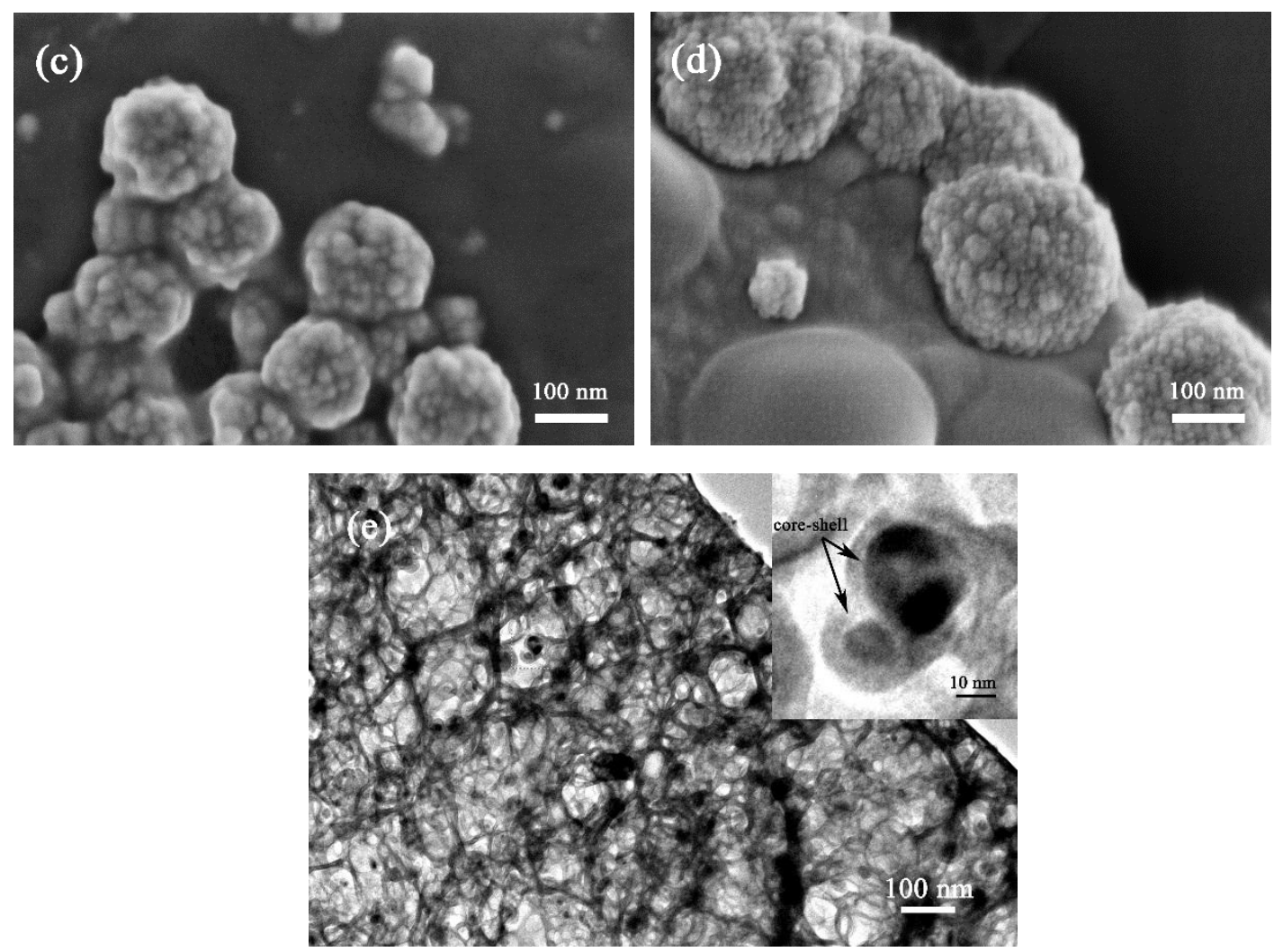

Figure 4. SEM images of $\mathrm{Cu}_{2} \mathrm{O}$ nanosphere (a), $\mathrm{GO} / \mathrm{Cu}_{2} \mathrm{O}-0.1$ (b), GO/Cu $2 \mathrm{O}-0.5$ (c) and $\mathrm{GO} / \mathrm{Cu}_{2} \mathrm{O}-1$ (d), along with the TEM image of $\mathrm{GO} / \mathrm{Cu}_{2} \mathrm{O}-0.5$ (e).

The SEM images of the nanosphere-shapes for all the samples are shown in Figure 4(a-d). The particle diameter of $\mathrm{Cu}_{2} \mathrm{O}$ nanospheres (Figure 4(a)) is under $100 \mathrm{~nm}$ and the nanospheres are aggregated into clusters in order to minimize the surface energy. The aggregation was occurred during the reduction reaction of $\mathrm{Cu}^{2+}$ and hydrazine. However, for the GO-modified samples, the sizes and the dispersity of nanospheres increase with the increasing of the additive amount of GO, which indicates hydrophilic oxygen functional groups on the surface of GO sheets [28] play a role in the formation of larger and dispersive nanospheres. These groups provide the sites for the growth and separation of newly formed $\mathrm{Cu}_{2} \mathrm{O}$ nanospheres by the aggregating the reactant, like $\mathrm{Cu}^{2+}, \mathrm{OH}^{-}$, hydrazine and etc. So too much of these groups leads to excessive aggregation of the ions and excessive growth of nanospheres, and thus the diameters increase form less than $100 \mathrm{~nm}$ (Figure 4(a)) to around $200 \mathrm{~nm}$ (Figure 4(d)) and the particle size of $\mathrm{Cu}_{2} \mathrm{O}$ was too big to be covered by $\mathrm{GO}$ sheets. On the contrary, too little of these groups makes clusters or excessively aggregated particles as $\mathrm{GO} / \mathrm{Cu}_{2} \mathrm{O}-0.1$ (Figure $4(\mathrm{~b})$ ) and the bare $\mathrm{Cu}_{2} \mathrm{O}$ nanospheres because of the unrestraint of growing positions. $0.5 \mathrm{wt} \%$ of GO addition may be a proper amount which can lead to the formation of core-shell structure, like $\mathrm{Cu}_{2} \mathrm{O} @ \mathrm{GO}$ (Figure 4(c)) and it was further revealed through TEM (Figure 4(e)). The $\mathrm{Cu}_{2} \mathrm{O}$ cores with the diameter at around $30 \mathrm{~nm}$ were covered by and effectively linked though the GO nano-sheets. The GO shell exhibited wrinkled and rough texture due to the flexible and extremely thin nature of the GO nano-sheets [25, 37]. These large wrinkled $\mathrm{GO}$ sheets covering numerous small $\mathrm{Cu}_{2} \mathrm{O}$ cores may enhance the separation and transfer of charges.

In order to investigate the species on the surface of $\mathrm{Cu}_{2} \mathrm{O}$ that enhance the visible light absorption, atomic 
compositions analysis from the $\mathrm{Cu} 2 \mathrm{p}, \mathrm{O} 1 \mathrm{~s}$ and $\mathrm{C} 1 \mathrm{~s}$ spectra were performed (Table 2). Atomic compositions of $\mathrm{Cu}(\mathrm{I})$ and $\mathrm{O}-\mathrm{Cu}$ for $\mathrm{Cu}_{2} \mathrm{O}-\mathrm{NS}$ have the stoichiometric ratio approximates to 2:1 and neither metal copper nor $\mathrm{Cu}$ (II) was detected, which means the addictive amount of hydrazine is appropriate for the reduction. However, for all GO-modified samples, the formation of $\mathrm{Cu}$ (II) may be attributed to 1) $\mathrm{GO}$ sheets cover the particles of $\mathrm{Cu}$ oxides and prevent the further reduction for $\mathrm{CuO}$ particle or 2) $\mathrm{GO} / \mathrm{GO}$ has higher oxidation-reduction potential than $\mathrm{Cu}^{+} / \mathrm{Cu}^{2+}$, which leads to easier reduction of GO sheets than $\mathrm{Cu}^{2+}$. Further discussion is performed in section 3.2. Neither amounts of $\mathrm{Cu}$ (I) nor amounts of $\mathrm{Cu}$ (II) sharply decreased with the increasing of GO addition, which suggests that GO was formed on the surface rather than being mixed with the lattices of copper oxides. Meanwhile, both the atomic amount of $\mathrm{sp}^{2}$ and $\mathrm{sp}^{3}$ carbon for $\mathrm{GO} / \mathrm{Cu}_{2} \mathrm{O}-0.5$ were the largest among all, which suggests that GO sheets covered the larger surface area for $\mathrm{GO} / \mathrm{Cu}_{2} \mathrm{O}-0.5$ than that of $\mathrm{GO} / \mathrm{Cu}_{2} \mathrm{O}-0.1$ or $\mathrm{GO} / \mathrm{Cu}_{2} \mathrm{O}-1$ and the core-shell structure was possibly formed on the surface of $\mathrm{GO} / \mathrm{Cu}_{2} \mathrm{O}-0.5$. This result is in line with the sharp peaks on the XRD patterns and nanosphere-structure of SEM images. Beside, a large amount of oxygen-carbon compositions (O-C, $\mathrm{O}=\mathrm{C}, \mathrm{C}-\mathrm{O}$ and $\mathrm{O}-\mathrm{C}=\mathrm{O}$ ) were detected on the GO-modified samples while no such compositions were detected on $\mathrm{Cu}_{2} \mathrm{O}-\mathrm{NS}$, which indicates the oxygen-carbon compositions come from the groups on the surface of GO.

Table 2-Atomic compositions (\%) measured for the chemical species from the $\mathrm{Cu} 2 \mathrm{p}, \mathrm{O} 1 \mathrm{~s}$ and $\mathrm{C}$ 1s spectra.

\begin{tabular}{cccccccccc}
$\begin{array}{c}\text { Species } \\
\text { Samples }\end{array}$ & $\mathrm{Cu}(\mathrm{I})$ & $\mathrm{Cu}(\mathrm{II})$ & $\mathrm{O}-\mathrm{Cu}$ & $\mathrm{O}-\mathrm{C}$ & $\mathrm{O}=\mathrm{C}$ & $\mathrm{C} \mathrm{sp}^{2}$ & $\mathrm{C} \mathrm{sp}^{3}$ & $\mathrm{C}-\mathrm{O}$ & $\mathrm{O}-\mathrm{C}=\mathrm{O}$ \\
$\mathbf{C} \mathbf{C u}_{\mathbf{2}} \mathbf{O}-\mathbf{N S}$ & 72.96 & 0 & 27.04 & 0 & 0 & 0 & 0 & 0 & 0 \\
$\mathbf{G O} / \mathbf{C u}_{\mathbf{2}} \mathbf{O}-\mathbf{0 . 1}$ & 23.4 & 9.26 & 19.8 & 1.06 & 1.4 & 7.03 & 4.7 & 4.88 & 28.47 \\
$\mathbf{G O} / \mathbf{C u}_{\mathbf{2}} \mathbf{O}-\mathbf{0 . 5}$ & 10 & 7.44 & 12.44 & 14.46 & 2.87 & 10.22 & 11.84 & 8.01 & 22.72 \\
$\mathbf{G O} / \mathbf{C u}_{\mathbf{2}} \mathbf{O}-\mathbf{1}$ & 9.55 & 4.9 & 9.36 & 25.69 & 7.74 & 6.59 & 6.99 & 9.84 & 19.34 \\
\hline
\end{tabular}

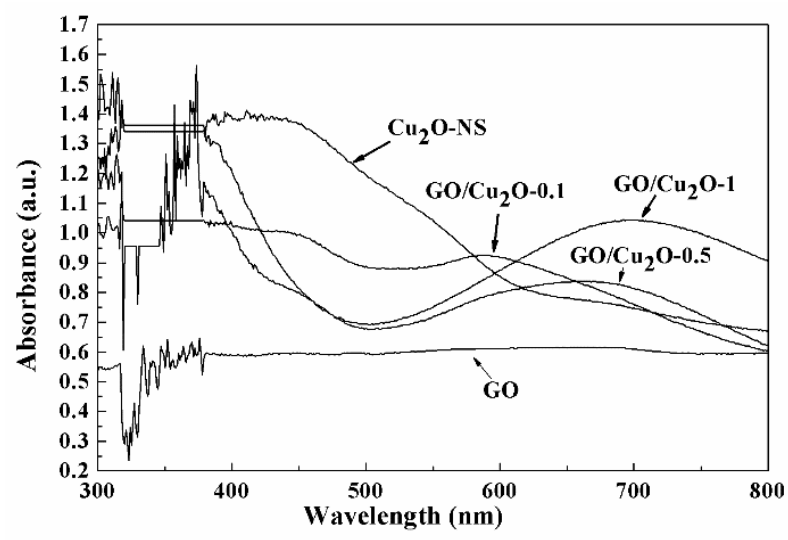

Figure 5. UV-vis absorption spectra of $\mathrm{Cu}_{2} \mathrm{O}$ nanosphere and the GO-modified samples.

The GO can distinctly change the absorption region of $\mathrm{Cu}_{2} \mathrm{O}$ nanosphere as showed in Figure 5. The doping of $\mathrm{GO}$ on the surface $\mathrm{Cu}_{2} \mathrm{O}$ nanosphere can slightly reduce the visible light absorption (400-500 $\mathrm{nm}$ ) because of the reflection of GO sheets. The spectrum of GO in the visible light region is flat (around 
0.6 a.u.) and the absorbances are much lower than those of the GO-modified samples. The red shift of the absorbance for the GO-modified samples were increasing obviously with the increasing of GO doping, which indicates the sample can enlarge the region of visible light absorption. It may be attributed to the easier transfer of electrons between $\mathrm{Cu}_{2} \mathrm{O}$ and $\mathrm{GO}$ than on $\mathrm{Cu}_{2} \mathrm{O}$ surfaces under irradiation instead of the enhancement of light absorption caused by GO addition.

Band gap, conduction band edge and valence band edge are three important parameters for semiconductor photocatalysts, and they can be calculation form the UV-vis absorption spectra. The values of band gaps for $\mathrm{Cu}_{2} \mathrm{O}$ nanosphere and the $\mathrm{GO}$-modified samples are estimated from the plot of the $(\alpha h v)^{2}$ versus photon energy $(\mathrm{hv})[4,38]$ as shown in Table 3. The band gap of $\mathrm{Cu}_{2} \mathrm{O}-\mathrm{NS}$ was estimated to be $1.90 \mathrm{eV}$, which was in the reported band gap region of $\mathrm{Cu}_{2} \mathrm{O}(1.9 \sim 2.2 \mathrm{eV})$ [7, 8]. The band gaps of the GO-modified samples was narrowed from $1.02 \mathrm{eV}$ to $0.52 \mathrm{eV}$ with the increasing of GO addition. In order to investigate the band edges of $\mathrm{Cu}_{2} \mathrm{O}$ nanosphere and the GO-modified samples, two widely-used equations for band edge calculation are showed below:

$$
\begin{aligned}
& E_{C B}=\chi-E_{c}-\frac{1}{2} E_{g} \quad(\text { Equation 1) } \\
& E_{V B}=E_{g}+E_{C B} \quad(\text { Equation 2) }
\end{aligned}
$$

$\mathrm{E}_{\mathrm{CB}}$ is the conduction band edge of a semiconductor at the point of zero charge. $\chi$ is the absolute electronegativity[39] of the semiconductor, expressed as the geometric mean of the absolute electronegativity of the constituent atoms, which is defined as the arithmetic mean of the atomic electron affinity and the first ionization energy. $\mathrm{E}_{\mathrm{c}}$ is the energy of free electrons on the hydrogen scale $(\sim 4.5 \mathrm{eV})$. $\mathrm{E}_{\mathrm{g}}$ is the band gap of the semiconductor [4, 38]. $\chi$ values for $\mathrm{Cu}_{2} \mathrm{O}-\mathrm{NS}, \mathrm{GO} / \mathrm{Cu}_{2} \mathrm{O}-0.1, \mathrm{GO} / \mathrm{Cu}_{2} \mathrm{O}-0.5$ and $\mathrm{GO} / \mathrm{Cu}_{2} \mathrm{O}-1$, which were calculated according to the measured atomic compositions (Table 2), are 5.16, 5.85, 6.25 and 6.46. Their conduction band edges and valence band edges were also shown in Table 3. The conduction and valence band edge of the $\mathrm{Cu}_{2} \mathrm{O}$ nanosphere are $-0.29 \mathrm{eV}$ and $1.61 \mathrm{eV}$, which are approximated to the experimental and theoretical[40] results. Although the band gaps of all samples are avail to absorb visible light, the potentials of conduction band edges of the GO-modified samples are too positive to reduce $\mathrm{H}^{+}$, which suggests that GO-modified samples are not fit for catalyzing the water splitting reaction and their original structures must be change during irradiation.

Table 3-Band gaps, conduction band edges and valence band edges of $\mathrm{Cu}_{2} \mathrm{O}$ - NS and the GO-modified samples.

\begin{tabular}{cccc} 
Sample & Band gaps $(\mathbf{e V})$ & $\begin{array}{c}\text { Conduction band } \\
\text { edge }(\mathbf{e V})\end{array}$ & $\begin{array}{c}\text { Valence band edge } \\
(\mathbf{e V})\end{array}$ \\
$\mathbf{C u} \mathbf{O}-\mathbf{N S}$ & 1.90 & -0.29 & +1.61 \\
$\mathbf{G O} / \mathbf{C u}_{\mathbf{2}} \mathbf{O}-\mathbf{0 . 1}$ & 1.47 & +0.62 & +2.09 \\
$\mathbf{G O} / \mathrm{Cu}_{\mathbf{2}} \mathbf{O}-\mathbf{0 . 5}$ & 1.38 & +1.06 & +2.44 \\
$\mathbf{G O} / \mathbf{C u}_{\mathbf{2}} \mathbf{O}-\mathbf{1}$ & 1.26 & +1.33 & +2.59 \\
$\mathrm{Cu}_{\mathbf{2}} \mathbf{O}$ (theoretical, [40]) & 2.20 & -0.28 & +1.92 \\
\hline
\end{tabular}




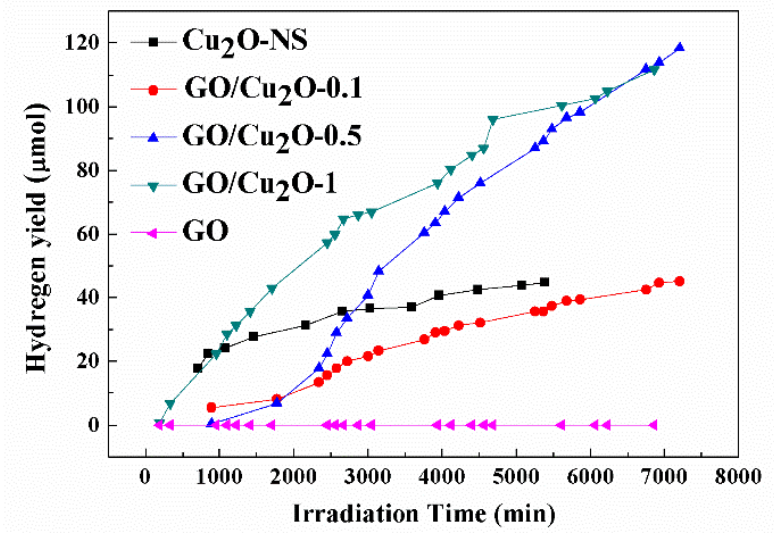

Figure 6. Photocatalytic performance of $\mathrm{Cu}_{2} \mathrm{O}-\mathrm{NS}, \mathrm{GO}$ and the GO-modified samples.

Figure 6 shows the photocatalytic performance of $\mathrm{Cu}_{2} \mathrm{O}$ - NS and the GO-modified samples. During more than 5000 minutes irradiation by visible light, hydrogen yields of all samples increase steadily without inactivation. $\mathrm{GO} / \mathrm{Cu}_{2} \mathrm{O}-0.5$ and $\mathrm{GO} / \mathrm{Cu}_{2} \mathrm{O}-1$ have higher hydrogen yields than that of $\mathrm{Cu}_{2} \mathrm{O}-\mathrm{NS}$ after 1000 and 3000 minutes' irradiation, respectively. At the $5387^{\text {th }}$ minute, the hydrogen yields of $\mathrm{GO} / \mathrm{Cu}_{2} \mathrm{O}-0.5$ and $\mathrm{GO} / \mathrm{Cu}_{2} \mathrm{O}-1$ were 89.3 and $96.0 \mu \mathrm{mol}$, respectively, which were 2.0 and 2.2 times as large as that of $\mathrm{Cu}_{2} \mathrm{O}-\mathrm{NS}(44.6 \mu \mathrm{mol})$. However, the hydrogen yield of $\mathrm{GO} / \mathrm{Cu}_{2} \mathrm{O}-0.1$ was even worse than that of the $\mathrm{Cu}_{2} \mathrm{O}-\mathrm{NS}$. It may be attributed to pore cover and surface area reduce. For $\mathrm{GO} / \mathrm{Cu}_{2} \mathrm{O}-0.5$ and $\mathrm{GO} / \mathrm{Cu}_{2} \mathrm{O}-1$, their hydrogen yields were also less than $\mathrm{Cu}_{2} \mathrm{O}$-NS before 1000 and 3000 minutes' irradiation, respectively. It suggests that the structures change during irradiation, which will be discussed in the section 3.2. Besides, bare GO with poor light absorption have no hydrogen production, which indicates that GO plays a role as the co-catalyst to provide carbon sheets for core-shell structure forming.

\subsection{Photocatalytic mechanism analysis}

In order to investigate how the structure change and the effect on photocatalytic mechanism, SEM, XPS, UV-vis absorption analysis and photoluminescence (PL) for $\mathrm{Cu}_{2} \mathrm{O}-\mathrm{NS}$ and $\mathrm{GO} / \mathrm{Cu}_{2} \mathrm{O}-0.5$ after irradiation were carried out. They were denoted as $\mathrm{Cu}_{2} \mathrm{O}-\mathrm{NS}$-af and $\mathrm{GO} / \mathrm{Cu}_{2} \mathrm{O}-0.5$-af, respectively.

Figure 7 is the XPS spectra for $\mathrm{Cu} 2 \mathrm{p}$ and $\mathrm{C} 1 \mathrm{~s}$ of $\mathrm{GO} / \mathrm{Cu}_{2} \mathrm{O}-0.5$ before and after irradiation. It shows that the $\mathrm{Cu}^{2+}$ species, such as $\mathrm{Cu}^{2+} 2 \mathrm{p}_{1 / 2}$ and $\mathrm{Cu}^{2+} 2 \mathrm{p}_{3 / 2}$, take a large proportion with three strong satellite peaks before irradiation (Figure 7(A)). However, the $\mathrm{Cu}^{2+}$ species can hardly be detected after irradiation and only two strong peaks referred to $\mathrm{Cu}^{+} 2 \mathrm{p}_{1 / 2}$ and $\mathrm{Cu}^{+} 2 \mathrm{p}_{3 / 2}$ were detected, which indicate that the copper dioxide particles may be reduced by the photo-generated electrons. Figure 7(B) shows that the peaks for $\mathrm{C}=\mathrm{O}$ and $\mathrm{C}-\mathrm{O}$ of $\mathrm{GO} / \mathrm{Cu}_{2} \mathrm{O}-0.5$ are much larger than the $\mathrm{C} \mathrm{sp}{ }^{2}$ and $\mathrm{C} \mathrm{sp}$, and the atomic percentages of $\mathrm{C} \mathrm{sp}^{2}$ and $\mathrm{C} \mathrm{sp}{ }^{3}$ are almost the same (Table 2). For $\mathrm{GO} / \mathrm{Cu}_{2} \mathrm{O}-0.5$-af, the contents of $\mathrm{C}=\mathrm{O}$ and $\mathrm{C}-\mathrm{O}$ species decrease sharply because some organic groups like carboxyl and carbonyl can be degraded to carbon dioxide or other dissociative composition during visible light irradiation [41], and this decrease also enlarges the atomic percentages of $\mathrm{C} \mathrm{sp}^{2}$ and $\mathrm{C} \mathrm{sp}$. But the percentages of $\mathrm{C} \mathrm{sp}$ are much larger than that of $\mathrm{C} \mathrm{sp}{ }^{3}$. By comparing the atomic compositions for $\mathrm{GO} / \mathrm{Cu}_{2} \mathrm{O}-0.5$ and $\mathrm{GO} / \mathrm{Cu}_{2} \mathrm{O}-0.5$-af (Table $\mathrm{S} 1$ ), it was found that the ratio of $\mathrm{C} \mathrm{sp}^{2}$ to $\mathrm{C} \mathrm{sp}^{3}$ increase from 0.86 to 1.22 while a part of covered GO was desquamated (Figure 7(D)) and the GO shell was thinner and more smooth 
(Figure 7(E)), which suggests that a part of $\mathrm{sp}^{3}$ carbon was degraded during irradiation. In the $\mathrm{Cu} 2 \mathrm{p}$ spectrum of $\mathrm{Cu}_{2} \mathrm{O}-\mathrm{NS}$ (Figure 7(C)), it shows that $\mathrm{Cu}$ (II) species appeared. The valence band edge potential of $\mathrm{Cu}_{2} \mathrm{O}-\mathrm{NS}(1.61 \mathrm{eV})$ is more positive than $\mu_{\mathrm{Cu}^{+} / \mathrm{Cu}^{2+}}(0.18 \mathrm{eV})$ and $\mu_{\mathrm{O}_{2} / \mathrm{H}_{2} \mathrm{O}}(1.23 \mathrm{eV})$, which indicates that a part of $\mathrm{Cu}$ (I) species of was oxidized to $\mathrm{Cu}$ (II) by the photo-generated holes or generated oxygen from the water splitting reaction.
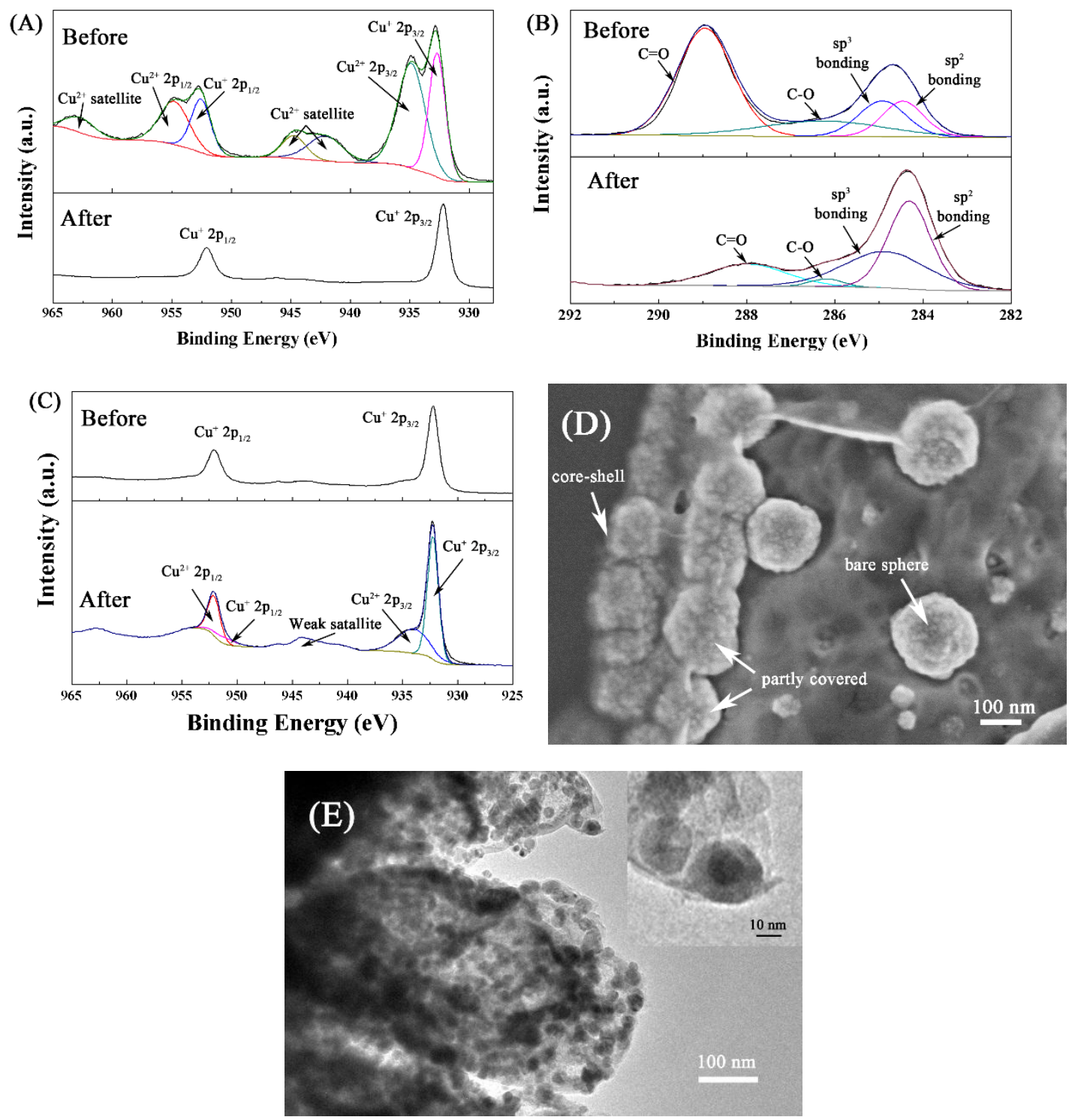

Figure 7. XPS spectra for $\mathrm{Cu} 2 \mathrm{p}(\mathrm{A})$ and $\mathrm{C} 1 \mathrm{~s}(\mathrm{~B})$ of $\mathrm{GO} / \mathrm{Cu}_{2} \mathrm{O}-0.5$ and $\mathrm{Cu} 2 \mathrm{p}(\mathrm{C})$ of $\mathrm{Cu}_{2} \mathrm{O}-\mathrm{NS}$ before and after irradiation along with SEM (D) and TEM (E) image of $\mathrm{GO} / \mathrm{Cu}_{2} \mathrm{O}-0.5$-af.

For more details of the semiconductor properties of $\mathrm{Cu}_{2} \mathrm{O}-\mathrm{NS}$-af and $\mathrm{GO} / \mathrm{Cu}_{2} \mathrm{O}-0.5$-af, such as band gap, conduction band edge and valence band edge, were calculated (Table S2) according to the UV-Vis absorption spectra and XPS analysis. The conduction band edge $(-0.10 \mathrm{eV})$ and valence band edge $(1.80 \mathrm{eV})$ potentials of $\mathrm{Cu}_{2} \mathrm{O}-\mathrm{NS}$-af shifted towards positive region compared to those of $\mathrm{Cu}_{2} \mathrm{O}-\mathrm{NS}$ (Table 3), because the increase of oxygen atomic percentage leads to the increase of the absolute electronegativity ( $\chi$ values) according to equation 1 and 2 . For all GO-modified samples, both $\mathrm{CuO}$ and 
$\mathrm{Cu}_{2} \mathrm{O}$ can be detected with weak XRD reflection and strong XPS signal on the GO-modified samples, it indicates that $\mathrm{CuO}$ and $\mathrm{Cu}_{2} \mathrm{O}$ particles are conjugated instead of being mixed up or highly separated with each other which leads to the electrons flowed from $\mathrm{Cu}_{2} \mathrm{O}$ with a lower $\chi$ values of $5.33 \mathrm{eV}$ to $\mathrm{CuO}$ with a higher $\chi$ values of $5.81 \mathrm{eV}$ until the chemical potential become equal [39]. The potential of this photo-generated electron flow formed by excitation of $\mathrm{Cu}_{2} \mathrm{O}$ was calculated to be $-0.27 \mathrm{eV}$, which is more negative than that of $\mu_{\mathrm{Cu}^{2+} / \mathrm{Cu}^{+}}(-0.18 \mathrm{eV})$ and may lead to the reduction of $\mathrm{Cu}$ (II) oxide and the composition of oxygen bonding on the surface. Table S2 also shows that conduction band edge of $\mathrm{GO} / \mathrm{Cu}_{2} \mathrm{O}-0.5$-af was calculated to be $-0.02 \mathrm{eV}$, which is much negative than that of $\mathrm{GO} / \mathrm{Cu}_{2} \mathrm{O}-0.5$ and negative enough to reduce $\mathrm{H}^{+}$to hydrogen during photocatalysis. It also suggest that a part of photoenergy had to be used to reduce $\mathrm{Cu}$ (II) oxide and GO instead of producing hydrogen at the beginning of photocatalysis.

Figure 8 shows the hydrogen production rate of $\mathrm{Cu}_{2} \mathrm{O}-\mathrm{NS}$ and the GO-modified samples. The hydrogen production rate of $\mathrm{Cu}_{2} \mathrm{O}-\mathrm{NS}$ was reducing from the top rate of $1.6 \mu \mathrm{mol} / \mathrm{h}$ to around $0.5 \mu \mathrm{mol} / \mathrm{h}$, and the reduction of production rate was predicted by the XPS analysis and the semiconductor properties calculation from UV-Vis absorption spectra. It also indicates the $\mathrm{Cu}_{2} \mathrm{O}$ nanosphere was a kind of active photocatalysts with poor stability. After being modified by $\mathrm{GO}, \mathrm{GO} / \mathrm{Cu}_{2} \mathrm{O}-0.1, \mathrm{GO} / \mathrm{Cu}_{2} \mathrm{O}-0.5$ and $\mathrm{GO} / \mathrm{Cu}_{2} \mathrm{O}-1$ have enhance stability of hydrogen production rate. Although $\mathrm{GO} / \mathrm{Cu}_{2} \mathrm{O}-1$ had higher rate than $\mathrm{GO} / \mathrm{Cu}_{2} \mathrm{O}-0.5$, its stability performed worse. It may be attributed to the oxidation of $\mathrm{Cu}_{2} \mathrm{O}$ nanosphere because the nanospheres were only grown on the surface of GO (Figure 4(d)). Hydrogen production rate of $\mathrm{GO} / \mathrm{Cu}_{2} \mathrm{O}-0.5$ was gently increasing and it reached the highest point and become stable at the $3100^{\text {th }}$ minutes. It is the core-shell structure that leads to the gentle reduction of $\mathrm{CuO}$ and GO.

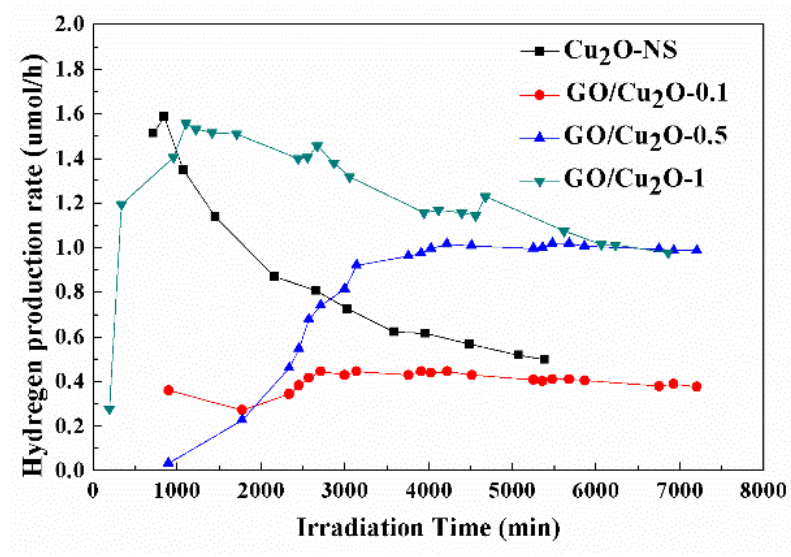

Figure 8. Hydrogen production rate of $\mathrm{Cu}_{2} \mathrm{O}-\mathrm{NS}$ and the GO-modified samples.

The high electronegativity of oxygen atoms on carbon sheets causes the charge flow that exerts p-type semiconductivity to GO.[28, 42] In order to investigate the relationship between this charge flow on the surface and the structure change during irradiation, photoluminescence spectra (PL) of were carried out. Figure 9 shows the PL spectra of $\mathrm{GO} / \mathrm{Cu}_{2} \mathrm{O}-0.5$ before, after 1000 minutes and 2000 minutes irradiation (denoted as "0 min", “1000 min" and "2000 min", respectively) with an excitation wavelength of $350 \mathrm{~nm}$. The extremely reduced PLintensity indicates the mitigated charge recombination in comparison to $\mathrm{Cu}_{2} \mathrm{O}$ [14] caused by the faster electrons transfer between $\mathrm{Cu}_{2} \mathrm{O}$ and GO. From the above discussion of the XPS 
spectra (Figure 7), it suggests that it is the new-forming $\mathrm{sp}^{2}$ carbon leads to this mitigated electron-hole recombination.

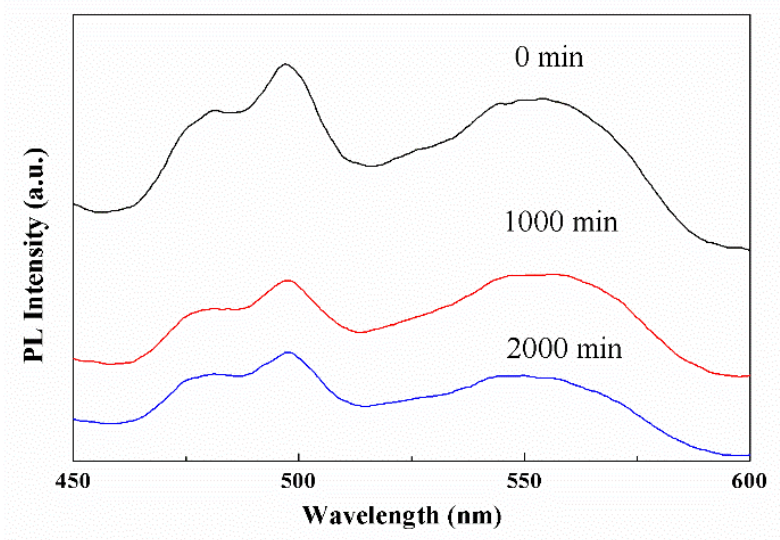

Figure 9. Photoluminescence spectra of $\mathrm{GO} / \mathrm{Cu}_{2} \mathrm{O}-0.5$ before, after 1000 minutes and 2000 minutes irradiation (denoted as "0 min", "1000 min" and "2000 min”, respectively) with an excitation wavelength of $350 \mathrm{~nm}$.

In summary, the photocatalytic mechanism of GO-modified $\mathrm{Cu}_{2} \mathrm{O}$ can be descripted as the follow steps: (a) $\mathrm{CuO}$ was reduced gradually by the photo-generated electrons from the conduction band edge of $\mathrm{Cu}_{2} \mathrm{O}$, which leads to negative removing of conduction band edge potentials of catalyst. (b) A part of GO was reduced and the amount of $\mathrm{sp}^{2}$ carbon increased, which leads to the increase of electroconductibility and enhancement of charge transfer. (c) Hydrogen was evolved on the surface of $\mathrm{Cu}_{2} \mathrm{O}$ catalysts while the photo-generated electrons from $\mathrm{Cu}_{2} \mathrm{O}$ cores were transferred through the newly formed $\mathrm{sp}^{2}$ carbon.

\section{Conclusion}

The one-step method for synthesize cuprous oxide nanosphere without any additive surfactant in room temperature and atmospheric pressure was examined to be an easy and efficient method that the diameter of the nanospheres was less than $100 \mathrm{~nm}$. The $\mathrm{Cu}_{2} \mathrm{O}$ nanospheres were well-dispersed and formed the core-shell structure with 5 wt.\% GO. The partial reduction of GO leads to the increase of atomic percentage of $\mathrm{sp}^{2}$ carbon (graphene sheets). Its better conductivity plays an important role in mitigating electron-hole recombination and enhancing electron transfer between $\mathrm{Cu}_{2} \mathrm{O}$ and $\mathrm{GO}$ and thus enhance the photocatalytic activity. The highest hydrogen yields for GO-modified samples $(118.3 \mu \mathrm{mol})$ were more than twice as large as that of bare $\mathrm{Cu}_{2} \mathrm{O}$ nanosphere $(44.6 \mu \mathrm{mol})$.

\section{Acknowledgement}

The authors gratefully acknowledge the financial support of CAS Renewable Energy Key Lab., National Science Foundation of China (51576201), Natural Science Foundation of Guangdong Province (2015A030312007), Guangdong Science and Technology Project (2013B050800007) and Guangzhou Science and Technology Project (2013J4500027).

\section{REFERENCES}

[1] Zhang P, Wang T, Chang XX, Gong JL. Effective Charge Carrier Utilization in Photocatalytic Conversions. Accounts Chem Res. 2016;49:911-21. 
[2] Zhao Y-F, Yang Z-Y, Zhang Y-X, Jing L, Guo X, Ke Z, et al. Cu2O Decorated with Cocatalyst MoS2 for Solar Hydrogen Production with Enhanced Efficiency under Visible Light. J Phys Chem C. 2014;118:14238-45.

[3] Huang Y, Yan CF, Guo CQ, Shi Y. Experimental and first-principles DFT study on oxygen vacancies on cerium dioxide and its effect on enhanced photocatalytic hydrogen production. Int J Hydrogen Energ. 2016;41:7919-26.

[4] Huang Y, Yan C-F, Guo C-Q, Huang S-L. Enhanced Photoreduction Activity of Carbon Dioxide over Co3O4/CeO2 Catalysts under Visible Light Irradiation. Int J Photoenergy. 2015:30808-.

[5] Hou J, Cheng H, Takeda O, Zhu H. Three-Dimensional Bimetal-Graphene-Semiconductor Coaxial Nanowire Arrays to Harness Charge Flow for the Photochemical Reduction of Carbon Dioxide. Angew Chem Int Edit. 2015;54:8480-4.

[6] Fujishima A, Honda K. Electrochemical Photolysis of Water at a Semiconductor Electrode. Nature. 1972;238:37-+.

[7] Almeida BM, Melo MA, Jr., Bettini J, Benedetti JE, Nogueira AF. A novel nanocomposite based on $\mathrm{TiO} 2 / \mathrm{Cu} 2 \mathrm{O} /$ reduced graphene oxide with enhanced solar-light-driven photocatalytic activity. Appl Surf Sci. 2015;324:419-31.

[8] Fan W, Yu X, Lu H-C, Bai H, Zhang C, Shi W. Fabrication of TiO2/RGO/Cu2O heterostructure for photoelectrochemical hydrogen production. Appl Catal B-Environ. 2016;181:7-15.

[9] Sun L, Wu X, Meng M, Zhu X, Chu PK. Enhanced Photodegradation of Methyl Orange Synergistically by Microcrystal Facet Cutting and Flexible Electrically-Conducting Channels. J Phys Chem C. 2014;118:28063-8.

[10] Tu K, Wang Q, Lu A, Zhang L. Portable Visible-Light Photocatalysts Constructed from Cu2O Nanoparticles and Graphene Oxide in Cellulose Matrix. J Phys Chem C. 2014;118:7202-10.

[11] Li B, Liu T, Hu L, Wang Y. A facile one-pot synthesis of Cu2O/RGO nanocomposite for removal of organic pollutant. J Phys Chem Solids. 2013;74:635-40.

[12] Liu Y, Yang G, Zhang H, Cheng Y, Chen K, Peng Z, et al. Enhanced visible photocatalytic activity of $\mathrm{Cu} 2 \mathrm{O}$ nanocrystal/titanate nanobelt heterojunctions by a self-assembly process. RSC Adv. 2014;4:24363-8.

[13] Yang L-f, Chu D-q, Wang L-m, Ge G, Sun H-1. Microemulsion-mediated synthesis of sedum rubrotinctum shaped $\mathrm{Cu} 2 \mathrm{O}$ architecture with efficient sunlight driven photocatalytic activity. RSC Adv. 2016;6:960-6.

[14] An X, Li K, Tang J. Cu2O/Reduced Graphene Oxide Composites for the Photocatalytic Conversion of CO2. ChemSusChem. 2014;7:1086-93.

[15] Bi F, Ehsan MF, Liu W, He T. Visible-Light Photocatalytic Conversion of Carbon Dioxide into Methane Using Cu2O/TiO2 Hollow Nanospheres. Chinese J Chem. 2015;33:112-8.

[16] Chang XX, Wang T, Zhang P, Wei YJ, Zhao JB, Gong JL. Stable Aqueous Photoelectrochemical CO2 Reduction by a Cu2O Dark Cathode with Improved Selectivity for Carbonaceous Products. Angew Chem Int Edit. 2016;55:8840-5.

[17] Handoko AD, Tang JW. Controllable proton and $\mathrm{CO} 2$ photoreduction over $\mathrm{Cu} 2 \mathrm{O}$ with various morphologies. Int J Hydrogen Energ. 2013;38:13017-22.

[18] Yeh T-F, Chan F-F, Hsieh C-T, Teng H. Graphite Oxide with Different Oxygenated Levels for Hydrogen and Oxygen Production from Water under Illumination: The Band Positions of Graphite Oxide. J Phys Chem C. 2011;115:22587-97.

[19] Yeh T-F, Chen S-J, Yeh C-S, Teng H. Tuning the Electronic Structure of Graphite Oxide through 
Ammonia Treatment for Photocatalytic Generation of H-2 and O-2 from Water Splitting. J Phys Chem C. 2013;117:6516-24.

[20] Luo JS, Steier L, Son MK, Schreier M, Mayer MT, Gratzel M. Cu2O Nanowire Photocathodes for Efficient and Durable Solar Water Splitting. Nano Lett. 2016;16:1848-57.

[21] Xi Z, Li C, Zhang L, Xing M, Zhang J. Synergistic effect of Cu2O/TiO2 heterostructure nanoparticle and its high H-2 evolution activity. Int J Hydrogen Energ. 2014;39:6345-53.

[22] Fang S, Xin Y, Ge L, Han C, Qiu P, Wu L. Facile synthesis of $\mathrm{CeO} 2$ hollow structures with controllable morphology by template-engaged etching of $\mathrm{Cu} 2 \mathrm{O}$ and their visible light photocatalytic performance. Appl Catal B-Environ. 2015;179:458-67.

[23] Xu H, Wang W, Zhu W. Shape evolution and size-controllable synthesis of Cu2O octahedra and their morphology-dependent photocatalytic properties. J Phys Chem B. 2006;110:13829-34.

[24] Feng L, Zhang C, Gao G, Cui D. Facile synthesis of hollow Cu2O octahedral and spherical nanocrystals and their morphology-dependent photocatalytic properties. Nanoscale Res Lett. 2012;7.

[25] Xu Y-T, Guo Y, Li C, Zhou X-Y, Tucker MC, Fu X-Z, et al. Graphene oxide nano-sheets wrapped $\mathrm{Cu} 2 \mathrm{O}$ microspheres as improved performance anode materials for lithium ion batteries. Nano Energy. 2015;11:38-47.

[26] Yin H, Wang X, Wang L, Nie Q, Zhang Y, Wu W. Cu2O/TiO2 heterostructured hollow sphere with enhanced visible light photocatalytic activity. Materials Research Bulletin. 2015;72:176-83.

[27] Babu SG, Vinoth R, Narayana PS, Bahnemann D, Neppolian B. Reduced graphene oxide wrapped $\mathrm{Cu} 2 \mathrm{O}$ supported on C3N4: An efficient visible light responsive semiconductor photocatalyst. APL Mater. $2015 ; 3$.

[28] Yeh T-F, Teng H. Graphite Oxide with Different Oxygen Contents as Photocatalysts for Hydrogen and Oxygen Evolution From Water. In: Weidner J, editor. Carbon Nanotubes and Nanostructures: From Fundamental Properties and Processes to Applications and Devices2012. p. 7-26.

[29] Wang Y, Pei Y, Xiong W, Liu T, Li J, Liu S, et al. New photocatalyst based on graphene oxide/chitin for degradation of dyes under sunlight. International Journal of Biological Macromolecules. 2015;81:477-82.

[30] Xu HL, Li XQ, Kang SZ, Qin LX, Li GD, Mu J. Noble metal-free cuprous oxide/reduced graphene oxide for enhanced photocatalytic hydrogen evolution from water reduction. Int $\mathbf{J}$ Hydrogen Energ. 2014;39:11578-82.

[31] Tran PD, Batabyal SK, Pramana SS, Barber J, Wong LH, Loo SCJ. A cuprous oxide-reduced graphene oxide ( $\mathrm{Cu} 2 \mathrm{O}-\mathrm{rGO})$ composite photocatalyst for hydrogen generation: employing rGO as an electron acceptor to enhance the photocatalytic activity and stability of $\mathrm{Cu} 2 \mathrm{O}$. Nanoscale. 2012;4:3875-8.

[32] Dubale AA, Su W-N, Tamirat AG, Pan C-J, Aragaw BA, Chen H-M, et al. The synergetic effect of graphene on $\mathrm{Cu} 2 \mathrm{O}$ nanowire arrays as a highly efficient hydrogen evolution photocathode in water splitting. J Mater Chem A. 2014;2:18383-97.

[33] Hummers WS, Offeman RE. Preparation of Graphitic Oxide. J Am Chem Soc. 1958;80:1339-.

[34] Cote LJ, Kim F, Huang JX. Langmuir-Blodgett Assembly of Graphite Oxide Single Layers. J Am Chem Soc. 2009;131:1043-9.

[35] Ai Z, Zhang L, Lee S, Ho W. Interfacial Hydrothermal Synthesis of Cu@Cu2O Core-Shell Microspheres with Enhanced Visible-Light-Driven Photocatalytic Activity. J Phys Chem C. 2009;113:20896-902.

[36] Zeng B, Chen X, Ning X, Chen C, Long H. ARCHITECTURE OF FLOWER-LIKE 
rGO/CNTs-LOADED CuxO NANOPARTICLES AND ITS PHOTOCATALYTIC PROPERTIES. Nano. $2013 ; 8$

[37] Dikin DA, Stankovich S, Zimney EJ, Piner RD, Dommett GHB, Evmenenko G, et al. Preparation and characterization of graphene oxide paper. Nature. 2007;448:457-60.

[38] Butler MA. Photoelectrolysis and Physical-Properties of Semiconducting Electrode Wo3. J Appl Phys. 1977;48:1914-20.

[39] Pearson RG. Absolute Electronegativity and Hardness - Application to Inorganic-Chemistry. Inorg Chem. 1988;27:734-40.

[40] Xu Y, Schoonen MAA. The absolute energy positions of conduction and valence bands of selected semiconducting minerals. Am Miner. 2000;85:543-56.

[41] Zhang Y-L, Guo L, Xia H, Chen Q-D, Feng J, Sun H-B. Photoreduction of Graphene Oxides: Methods, Properties, and Applications. Advanced Optical Materials. 2014;2:10-28.

[42] Lahaye RJWE, Jeong HK, Park CY, Lee YH. Density functional theory study of graphite oxide for different oxidation levels. Phys Rev B. 2009;79. 